\title{
ANALISIS HUBUNGAN ANTARA FAKTOR PERILAKU DENGAN KEJADIAN MALARIA DI WILAYAH KERJA PUSKESMAS MAYUMBA PROVINSI SULAWESI TENGAH
}

\author{
Fien Lumolo \\ ${ }^{2}$ Odi R. Pinontoan \\ ${ }^{2}$ Joy M. Rattu \\ Program Studi Epidemiologi Pascasarjana Fakultas Ilmu Kesehatan Masyarakat \\ ${ }^{2}$ Program Pascasarjana Fakultas Kesehatan Masyarakat \\ Universitas SamRatulangi Manado \\ Email: lumolofien@yahoo.com/082191360332
}

\begin{abstract}
Malaria is a re-emerging disease (can spread back by the large number) and still being a problem in Indonesia. This disease is caused by Plasmodium. This study aimed to analyze the risk factors towards malaria in This was an analytical observational study with a case control approach (retrospectively) in the working area of Mayumba Community Health Center, Morowali, Middle Celebes Province. Samples were 94 respondents and the ratio of cases and controls was 1:1, therefore, there were a total of 188 peoples obtained by using the simple random sampling. From the results it can be concluded that there was a significant relationship between behavioral factors (knowledge, attitude, be out of the house at night, and hanging clothes in the house) and the incidence of malaria in Mayumba Health Center. It is advisable to the District Health Department and Community Health Center Morowali Mayumba to conduct a survey aiming to determine entomology vector bionomic which will be useful against malaria.
\end{abstract}

Keywords: behavior, malaria incidence

\begin{abstract}
Abstrak: Malaria merupakan penyakit yang re-emerging (menular kembali secara massal) dan masih merupakan masalah di Indonesia. Penyakit menular ini disebabkan oleh Plasmodium. Penelitian ini bertujuan untuk menganalisis faktor risiko terhadap kejadian malariadi wilayah kerja Puskesmas Mayumba Kabupaten Morowali Provinsi Sulawesi Tengah. Jenis penelitian ialah observasional analitik dengan pendekatan case control (retrospektif). Besar sampel penelitian ini sebanyak 94 responden, dengan perbandingan antara kelompok kasus dan kontrol 1:1 sehingga total sampel sebanyak 188 orang. Cara pengambilan sampel menggunakan teknik simple random sampling. Dari penelitian dapat disimpulkan bahwa terdapat hubungan bermakna antara faktor perilaku (pengetahuan, sikap, keluar rumah pada malam hari, dan menggantung pakaian di dalam rumah) dengan kejadian malaria di Puskesmas Mayumba. Disarankan kepada Dinas Kesehatan Kabupaten Morowali dan Puskesmas Mayumba agar melakukan survei entomologi yang bertujuan untuk mengetahui bionomik vektor yang akan berguna dalam upaya penanggulangan malaria.
\end{abstract}

Kata kunci: perilaku, kejadian malaria 
Penyebaran penyakit malaria berbeda dari negara satu dengan negara yang lain, dari satu kabupaten dengan kabupaten lain, bahkan satu wilayah dengan wilayah lainnya. Malaria ditemukan dilebih dari 100 negara terutama terbatas pada daerah tropis dari benua Afrika, Asia dan Amerika Latin. Penduduk yang berisiko terkena malaria berjumlah sekitar 2,3 milyar atau $14 \%$ dari penduduk dunia. Sejak tahun 2000 sampai tahun 2012 rata-rata kematian akibat penyakit malaria pada semua kelompok umur sebesar $45 \%$ dan 51\% pada anak usia dibawah 5 tahun. ${ }^{1}$

Malaria pada penduduk Indonesia tahun 2013 adalah mengalami penurunan 1,9\% dibanding tahun 2007 (2,9\%), tetapi di Papua Barat mengalami peningkatan tajam jumlah penderita malaria. Prevalensi malaria tahun 2013 adalah 6,0\%. Lima provinsi dengan insiden dan prevalensi tertinggi adalah Papua (9,8\% dan 28,6\%), Nusa Tenggara Timur (6,8\% dan 23,3\%), Papua Barat (6,7\% dan 19,4\%), Sulawesi Tengah (5,1\%) dan 12,5\%), dan Maluku (3,8\% dan 10,7\%). Dari 33 provinsi di Indonesia, 15 provinsi mempunyai prevalensi malaria di atas angka nasional, sebagian besar berada di Indonesia Timur, hal ini disebabkan karena adanya keterbatasan sumber daya pemerintah dalam masalah tenaga dan dana serta tingginya perbedaan endemisitas antar daerah juga dianggap menjadi tantangan penanggulangan malaria. Provinsi di JawaBali merupakan daerah dengan prevalensi malaria lebih rendah dibanding provinsi lain. $^{2}$

Profil kesehatan Sulawesi Tengah tahun 2012, Kabupaten Morowali menempati urutan pertama untuk kategori daerah endemis sedang. Kasus malaria di Kabupaten Morowali sebanyak 1933 kasus dan angka Annual Parasite Incidence (API) 15,08\% (15,08 kasus per 1000 penduduk). Tahun 2013 jumlah kasus malaria mengalami penurunan yaitu sebanyak 690 kasus dengan API 5,4\% (5,4 kasus per 1000 penduduk). Angka ini masih jauh dari target Millenium Development Goals (MDGs) dan target eliminasi yaitu $<1 \%{ }^{2}$
Puskesmas Mayumba merupakan puskesmas yang berada diurutan kedua setelah Puskesmas Tinompo untuk kejadian malaria yang tinggi dngan jumlah penderita semakin bertambah setiap tahunnya. Pada tahun 2013, di puskesmas Mayumba terjadi KLB malaria dengan jumlah kasus 205, dan pada tahun 2014 menurun menjadi 141 kasus malaria. $^{3}$

Upaya pencegahan dan pemberantasan penyakit malaria telah dilaksanakan oleh Dinas Kesehatan Kabupaten Morowali di antaranya penyemprotan rumah penduduk, pembagian kelambu berinsektisida, dan pengobatan penderita. Kenyataannya sampai saat ini penyakit malaria di Kabupaten Morowali masih belum dapat diselesaikan dengan tuntas. Berdasarkan latar belakang di atas maka peneliti tertarik untuk melakukan penelitian tentang analisis hubungan antara faktor perilaku dengan kejadian malaria di Wilayah Kerja Puskesmas Mayumba Kabupaten Morowali Provinsi Sulawesi Tengah tahun 2014.

\section{METODE PENELITIAN}

Penelitian ini dilaksanakan di wilayah kerja Puskesmas Mayumba Kabupaten Morowali Provinsi Sulawesi Tengah. Populasi kasus adalah semua orang yang dalam sediaan darahnya ditemukan Plasmodium berdasarkan hasil pemeriksaan mikroskopis dan populasi kontrol adalah semua orang yang dalam sediaan darahnya tidak ditemukan Plasmodium berdasarkan hasil pemeriksaan mikroskopis di Puskesmas Mayumba. Sampel minimum sebanyak 94 orang. Perbandingan kasus : kontrol sebesar 1:1, sehingga total sampel keseluruhan sebesar 188 responden. Penelitian ini menggunakan rancangan case control. Pengumpulan data dilakukan dengan wawancara terstruktur dengan menggunakan kuesioner serta observasi untuk melengkapi data lingkungan. Pengolahan data dilakukan dengan menggunakan SPSS. Data dianalisis secara desktiptif dengan tabel distribusi frekuensi serta analisis bivariat dengan Odds Ratio yang disertai dengan narasi. 


\section{HASIL PENELITIAN}

\section{Analisis Univariat Karakteristik Responden}

Distribusi responden menurut kelompok umur pada kelompok kasus dan kelompok kontrol, dimana kelompok umur yang paling banyak adalah adalah $<25$ tahun sebanyak 71 responden $(37,8 \%)$ yang terdiri dari 37 responden (19,7\%) pada kelompok kasus dan sebanyak 34 responden $(18,1 \%)$ pada kelompok kontrol sedangkan kelompok umur yang paling sedikit ialah kelompok umur $>65$ tahun sebanyak 2 responden (1,0\%), pada kelompok kasus 1 responden (0,5\%) dan 1 responden (0,5\%) pada kelompok kontrol.

Jenis kelamin terbanyak ialah laki-laki yaitu sebanyak 112 responden (59,5\%) yang terdiri dari 47 responden (25\%) pada kelompok kasus dan 65 responden (34,5\%) pada kelompok kontrol. Sedangkan pada jenis kelamin perempuan sebanyak 76 responden $(40,4 \%)$ yang terdiri dari 47 responden (25\%) pada kasus dan 29 responden $(15,4 \%)$ pada kontrol.

Responden terbanyak dengan tingkat pendidikan SMP yaitu sebanyak 97 responden $(51,5 \%)$ yang terdiri dari 35 responden $(18,6 \%)$ pada kelompok kasus dan 62 responden (32,9\%) pada kelompok kontrol, sedangkan tingkatan pendidikan yang paling sedikit yaitu pada tingkatan pendidikan perguruan tinggi (PT) sebanyak 8 responden $(4,3 \%)$ yang terdiri dari 7 responden $(3,7 \%)$ pada kelompok kasus dan 1 responden $(0,1 \%)$ pada kelompok kontrol.

Responden menurut jenis pekerjaan paling banyak ialah responden yang bekerja sebagai petani/tukang ojek sbanyak 114 responden $(60,7 \%)$ yang terdiri dari 47 responden (25\%) pada kelompok kasus dan 67 responden (35,7\%) pada kelompok kontrol. Sedangkan yang paling sedikit ialah responden dengan jenis pekerjaan swasta yaitu 8 responden (4,2\%) yang terdiri dari 5 responden $(2,3 \%)$ pada kelompok kasus dan 3 responden (1,6\%) pada kelompok kontrol.

\section{Analisis Univariat Variabel Penelitian}

Responden terbanyak berpengetahuan baik yaitu sebanyak 105 responden $(55,8 \%)$ yang terdiri dari 42 responden $(22,3 \%)$ pada kelompok kasus dan 63 responden (33,5\%) pada kelompok kontrol, sedangkan yang berpengetahuan kurang pada kelompok kasus sebanyak 52 responden (27,6\%) dan pada kelompok kontrol sebanyak 31 responden (16,4\%).

Responden terbanyak memiliki sikap kurang baik yaitu 95 responden (50,5\%) yang terdiri dari 59 responden $(31,3 \%)$ pada kelompok kasus dan 36 responden (19,1\%) pada kelompok kontrol, sedangkan pada responden dengan sikap baik pada kelompok kasus sebanyak 35 responden $(18,6 \%)$ dan sebanyak 58 responden (30,8\%) pada kelompok kontrol.

Responden terbanyak adalah yang mempunyai kebiasan keluar rumah pada malam hari yaitu sebanyak 101 responden $(53,7 \%)$ yang terdiri dari 58 responden (30,8\%) pada kelompok kasus dan 43 responden $(22,8 \%)$ pada kelompok kontrol, sedangkan responden yang tidak mempunyai kebiasaan keluar rumah pada malam hari sebanyak 87 responden $(46,2 \%)$ yang terdiri dari 36 responden (19,1\%) pada kelompok kasus dan 51 responden $(27,1 \%)$ pada kelompok kontrol.

Responden terbanyak mempunyai kebiasaan menggantung pakaian di dalam rumah yaitu 109 responden (57,9\%) yang terdiri dari 63 responden (33,5\%) pada kelompok kasus dan 46 responden $(24,4 \%)$ pada kelompok kontrol, sedangkan responden yang tidak mempunyai kebiasaan menggantung pakaian di dalam rumah sebanyak 79 responden (42,0\%) yag terdiri dari 31 responden (16,4\%) pada kelompok kasus dan 48 responden $(25,5 \%)$ pada kelompok kontrol.

Responden paling banyak adalah yang tidak menggunakan kelambu pada waktu tidur malam hari yaitu 109 responden (57,9\%) yang terdiri dari 57 responden (30,3\%) pada kelompok kasus dan 52 responden $(27,6 \%)$ pada kelompok kontrol, sedangkan responden yang tidak mempunyai kebiasaan menggunakan 
kelambu sebanyak 79 responden $(42,0 \%)$ yang terdiri dari 37 responden $(19,6 \%)$ pada kelompok kasus dan 42 responden (22,3\%) pada kelompok kontrol.

\section{Analisis Bivariat}

Analisis secara bivariat dengan menggunakan uji square diperoleh hasil terdapat hubungan yang bermakna antara pengetahuan dengan kejadian malaria, yang ditandai dengn nilai $\mathrm{p}=0,000 ; \mathrm{OR}=0,397$ (95\%CI : 0,220-0,718). Apabila dilihat dari nilai $\mathrm{OR}=0,397$ maka pengetahuan merupakan faktor risiko terhadap kejadian malaria.

Analisis secara bivariat dengan menggunakan uji square diperoleh hasil terdapat hubungan yang bermakna antara pengetahuan dengan kejadian malaria, yang ditandai dengn nilai $\mathrm{p}=0,001 ; \mathrm{OR}=0,368$ (95\%CI : 0,204-0,664). Jika dilihat dari nilai $\mathrm{OR}=0,368$ maka sikap merupakan faktor risiko terhadap kejadian malaria.

Analisis secara bivariat dengan menggunakan uji square diperoleh hasil terdapat hubungan yang bermakna antara pengetahuan dengan kejadian malaria, yang ditandai dengn nilai $\mathrm{p}=0,041$; $\mathrm{OR}=1,911$ (95\%CI : 1,069-3,416). Jika dilihat dari nilai $\mathrm{OR}=1,911$ maka sikap merupakan faktor risiko terhadap kejadian malaria.

Hasil analisis secara bivariat dengan menggunakan uji square diperoleh hasil terdapat hubungan bermakna antara kebiasaan menggantung pakaian di dalam rumah dengan kejadian malaria, yang ditandai dengn nilai $\mathrm{p}=0,018 ; \mathrm{OR}=0,472$ (95\%CI : 0,261-0,851). Jika dilihat dari nilai $\quad \mathrm{OR}=0,472$ maka kebiasaan menggantung pakaian di dalam rumah merupakan faktor risiko terhadap kejadian malaria.

Hasil analisis secara bivariat dengan menggunakan uji square diperoleh hasil terdapat tidak ada hubungan yang bermakna antara penggnaan kelambu dengan kejadian malaria, yang ditandai dengn nilai $\mathrm{p}=0,554 ; \mathrm{OR}=0,804$ (95\%CI : 0,450-1,436). Jika dilihat dari nilai $\mathrm{OR}=$ 0,554 maka penggunaan kelambu pada saat tidur malam bukan merupakan faktor risiko terhadap kejadian malaria, dimana nilai $\mathrm{p}$ $(0,554)>0,05$.

\section{Analisis Multivariat \\ Pemilihan Variabel Kandidat Pemodelan}

Variabel yang memiliki nilai $\mathrm{p}<0,25$ dijadikan kandidat pemodelan yaitu, pengetahuan, sikap, tindakan keluar rumah pada malam hari, dan tindakan menggantung pakaian di dalam rumah. Semua variabel independen tetap dipertahankan dalam model karena mempunyai nilai p-value $<0,25$ (Tabel 1).

\section{Pemilihan Variabel Pemodelan}

Pada uji regresi logistik variabel yang memiliki nilai $\mathrm{p}>0,05$ satu persatu dikeluarkan dari model yaitu mulai dari variabel yang memiliki nilai $\mathrm{p}$ value lebih besar. Variabel yang mempunyai nilai $\mathrm{p}=$ $>0,05$ yaitu tindakan menggantung pakaian di dalam rumah $(\mathrm{p}=0,136)$ dan tindakan keluar rumah pada malam hari $(\mathrm{p}=0,079)$ (Tabel 2).

Tabel 1. Hasil Penyaringan Variabel Kandidat Pemodelan Multivariat

\begin{tabular}{lcc}
\hline \multicolumn{1}{c}{ Variabel } & p-value & OR \\
\hline Pengetahuan & 0,003 & 0,397 \\
Sikap & 0,001 & 0,368 \\
Tindakan keluar rumah pada malam hari & 0,041 & 1,911 \\
Tindakan menggantung pakaian & 0,018 & 0,472 \\
\hline
\end{tabular}


Jurnal e-Biomedik (eBm), Volume 3, Nomor 3, September-Desember 2015

Tabel 2. Hasil Uji Regresi Logisik Terhadap Masing-masing Variabel

\begin{tabular}{|c|c|c|c|c|}
\hline & Variabel & $\mathrm{P}$ value & OR & $95 \% \mathrm{CI}$ \\
\hline 1. & Pengetahuan & 0,009 & 0,435 & $0,232-0,815$ \\
\hline 2. & Sikap & 0,003 & 0,392 & 0,209-0,735 \\
\hline \multirow{2}{*}{$\begin{array}{l}3 . \\
4 .\end{array}$} & $\begin{array}{l}\text { Tindakan keluar rumah pada } \\
\text { malam hari }\end{array}$ & 0,079 & 1,748 & 0,938-3,255 \\
\hline & $\begin{array}{l}\text { Tindakan menggantung } \\
\text { pakaian di dalam rumah }\end{array}$ & 0,136 & 0,615 & $0,325-1,164$ \\
\hline
\end{tabular}

Faktor Perilaku Yang Paling Dominan terhadap Kejadian Malaria

Hasil analisis regresi logistik setelah melalui beberapa tahapan maka diperoleh hasil akhir bahwa dari 4 faktor perilaku yang berhubungan dengan kejadian malaria di wilayah kerja puskesmas mayumba, faktor paling dominan yaitu faktor tindakan menggantung pakaian di dalam rumah .

\section{BAHASAN \\ Analisis Univariat Karakteristik Responden}

Pengolahan data dan analisis data secara univariat untuk umur responden pada kelompok kasus dan kontrol, dimana kelompok umur yang paling banyak adalah $<25$ tahun sebanyak 71 responden (37,8\%). Usia < 25 tahun merupakan usia remaja yang sebagian besar masih mengalami masa pubertas. Berdasarkan pengamatan peneliti, responden yang berusia < 25 tahun banyak yang sering keluar rumah pada malam hari untuk berbagai alasan.

Responden menurut jenis kelamin terbanyak adalah laki-laki yaitu sebanyak 112 responden (59,5\%). Hasil penelitian ini didapatkan jenis kelamin laki-laki lebih banyak dibandingkan dengan perempuan untuk menderita malaria, hal ini disebabkan karena sebagian besar kaum laki-laki melakukan pekerjaan di luar rumah sampai malam hari dan ada juga ketika pulang bekerja setelah beristirahat sejenak langsung berkunjung ke rumah saudara, tetangga ataupun teman untuk berbagai alasan, misalnya mengobrol, main kartu atau hanya kumpul bersama untuk mengkonsumsi minuman keras (saguer, cap tikus) sampai larut malam.

Tingkat pendidikan responden terbanyak adalah tingkat SMP / SLTP sebanyak 97 responden. Semakin tinggi pendidikan seseorang maka akan semakin baik pengetahuan orang tersebut. Perilaku yang didasarkan pada pengetahuan akan berdampak lebih lama termasuk perilaku tentang tindakan pencegahan malaria. Pengetahuan seseorang didapat tidak hanya melalui pendidikan formal yang ditempuhnya tetapi bisa juga melalui penyuluhan, media masa dan media elektronik yang ada. ${ }^{4}$ Pada penelitian ini responden terbanyak berpendidikan SMP/SLTP, meskipun demikian pengetahuan responden terbanyak berada pada kategori baik.

Responden dengan jenis pekerjaan terbanyak adalah responden dengan pekerjaan petani/tukang ojek/peternak sebanyak 114 (60,6\%) responden. Pekerjaan petani/tukang ojek/peternak adalah jenis pekerjaan yang dilakukan diluar rumah bahkan dilakukan sampai malam hari. Sehingga memudahkan responden dengan jenis pekerjaan ini sangat berpeluang kontak dengan nyamuk anopheles.

Responden menurut pengetahuan tentang malaria terbanyak yaitu berpengetahuan baik yatu sebanyak 105 responden (55,8\%). Pengetahuan yang baik tentang pencegahan dan pengobatan malaria dari responden diharapkan akan 
menurunkan angka kejadian malaria di wilayah kerja puskesmas Mayumba.

Sikap terbanyak adalah responden dengan sikap kurang baik yaitu 95 responden (50,5\%). Hal ni disebabkan karena responden tidak mengaplikasikan dengan tindakan yang nyata tentang pencegahan malaria.

Responden yang terbiasa keluar rumah pada malam hari lebih banyak yaitu 101 responden $(53,7 \%)$. Pada malam hari, masyarakat bayak yang beraktivitas di luar rumah. Sebagai contoh, jika ada dero (tarian adat suku mori) masyarakat akan badero sampai larut malam, berkumpul bersama di teras-teras rumah atau di lingkungan depan rumah sambil bercerita dengan teman-teman sambil mengkonsumsi minuman keras (saguer dan captikus). Hal ini dapat disimpulkan bahwa kebiasaan beraktivitas di luar rumah pada malam hari dapat meningkatkan risiko terjadinya malaria.

Kebiasaan menggantung pakaian lebih banyak dilakukan oleh responden yang menderita malaria yaitu 63 responden (33,5\%) dibandingkan dengan responden yang tidak menderita malaria yaitu 46 responden (24,4\%). Hal ini dapat disimpulkan bahwa kebiasaan menggantung pakaian di dalam rumah dapat meningkatan risiko terjadinya malaria.

Penggunaan kelambu pada responden yang menderita malaria lebih sedikit (37 responden atau 19,6\%\%) dibandingkan dengan responden yang tidak menderita malaria (42 responden atau 22,3\%). Hal ini dapat disimpulkan bahwa tidak menggunakan kelambu pada waktu tidur malam hari dapat meningkatkan risiko terjadinya malaria.

\section{Hubungan Faktor Perilaku dengan Kejadian Malaria}

Pengetahuan yang baik dari masyarakat disebabkan karena masyarakat sudah mendapatkan penyuluhan dari petugas kesehatan tetapi dari yang pengetahuan baik masih ditemukan kasus malaria yang tinggi, sehingga dapat disimpukan bahwa pengetahuan yang baik dari masyarakat tidak diikuti dengan perilaku yang baik tentang pencegahan malaria.

Sikap merupakan kesediaan untuk bertindak tapi belum merupakan pelaksanaan tindakan. Sikap positif terhadap nilai-nilai kesehatan tidak selalu terwujud dalam satu tindakan nyata. Hal ini dikarenakan oleh alasan bahwa suatu tindakan tergantung situasi dan kondisi saat itu dan dukungan orang disekitarnya. ${ }^{4}$

Kondisi masyarakat yang ada di wilayah kerja puskesmas Mayumba memungkinkan berisiko untuk digigit nyamuk pada malam hari. Menurut peneliti hal ini disebabkan karena masyarakat di daerah ini banyak melakukan aktivitas di luar rumah pada malam hari dimana ada masyarakat yang bekerja sebagai petani dan tukang ojek yang bekerja sampai sore menjelang malam hari, ada juga kebiasaan masyarakat yang suka menginap di pondok kebun jika waktu panen akan tiba. Ada juga kebiasaan anak-anak muda yang suka duduk-duduk di pinggir jalan sambil mengobrol bersama sampai larut malam.

Kebiasaan menggantung pakaian di dalam rumah merupakan kebiasaan yang kurang baik. Di lihat dari karakterisik nyamuk terdapat beberapa golongan nyamuk yang memiliki sifat suka menempel di tempa yang lembab dan redup dalam rumah setelah menghisap darah misalnya menempel di tembok. Bila terdapat banyak pakaian yang menggantung dapat digunakan sebagai tempat persembunyian nyamuk. Hal ini tentu akan meningkatkan potensi nyamuk untuk kontak dengan manusia.

Pemakaian kelambu saat tidur merupakan upaya yang paling efekif untuk mencegah digigit nyamuk dibandingkan dengan upaya yang lain. Penggunaan kelambu lebih baik daripada penggunaan obat pengusir nyamuk dengan berbagai cara pemakaiannya yang berdampak kurang baik bagi pemakainya. Pemakaian kelambu pada saat tidur masih berpeluang untuk digigit nyamuk, karena harus dibuka dan ditutup meskipun kecil kemungkinan, 
tetapi masih ada peluang untuk nyamuk masuk menyelinap kedalam kelambu.

\section{SIMPULAN}

Dari hasil penelitian di wilayah kerja Puskesmas Mayumba Kabupaten Morowali Provinsi Sulawesi Tengah dapat disimpulkan bahwa terdapat hubungan bermakna antara pengetahuan, sikap, tindakan keluar rumah pada malam hari , dan tindakan menggantung pakaian dengan kejadian malaria tetapi tidak terdapat hubungan bermakna antara tindakan penggunaan kelambu pada saat tidur malam hari dengan kejadian malaria. Tindakan menggantung pakaian di dalam rumah merupakan variabel perilaku yang paling dominan terhadap kejadian malaria di wilayah kerja Puskesmas Mayumba Kabupaten Morowali Provinsi Sulawesi Tengah.

\section{SARAN}

1. Bagi Dinas Kesehatan, agar melakukan survei entomologi yang bertujuan untuk mengetahui bionomic vector yang akan berguna dalam upaya penanggulangan malaria, dan lebih meningkatkan kegiatan surveilens malaria secara menyeluruh, baik pemantauan parasit dan spesies vektor serta kepadatan vektor malaria.

2. Bagi petugas Puskesmas Mayumba, perlu dilakukan sosialisasi dan peyuluhan oleh petugas puskesmas tentang faktor risiko terhadap kejadian malaria pada masyarakat (penggunaan kelambu saat tidur malam, kebiasaan keluar rumah pada malam hari, pengetahuan dan sikap terhadap pencegahan dan pengobatan malaria serta faktor risiko lainnya).

3. Bagi peneliti selanjutnya kiranya dapat meneliti faktor lain yang tidak diteliti oleh penulis dalam tesis ini yang dapat menyebabkan penyakit malaria, misalnya dari segi faktor ekonomi sosial dan faktor lingkungan terhadap kejadian malaria.

4. Bagi masyarakat agar mengubah perilaku yang kurang baik yang menjadi faktor risiko terjadinya malaria antara lain tidak menggantung pakaian di dalam rumah, menggunakan kelambu yang baik dan benar pada waktu tidur malam, dan menggunakan pakaian lengkap jika keluar rumah pada saat malam hari (jaket, sarung).

\section{DAFTAR PUSTAKA}

1. WHO. World Malaria Report. Geneve, 2012.

2. Riset Kesehatan Dasar (Riskesdas). Jakarta: Badan Penelitian dan Pengembangan Kesehatan, Kemenkes RI, 2013.

3. Profil Tahunan P2 Malaria. Dinas Provinsi Sulawesi Tengah, 2014.

4. Profil Kesehatan Kabupaten Morowali tahun 2014. Dinas Provinsi Sulawesi Tengah, 2014. 